\title{
The Role of Excipients in the Stability of Triamcinolone Acetonide in Ointments
}

\author{
Anton J. P. van Heugten, ${ }^{1,2,5}$ (D) Wouter S. de Vries, ${ }^{2}$ Marian M. A. Markesteijn, ${ }^{2}$ \\ Roland J. Pieters, ${ }^{3}$ and H. Vromans ${ }^{1,2,4}$
}

Received 4 December 2017; accepted 14 January 2018; published online 15 February 2018

\begin{abstract}
Degradation of triamcinolone acetonide (TCA) in an ointment was investigated. TCA appeared to be concentrated in propylene glycol (PG) which in turn is dispersed in a lanolin-petrolatum mixture. Two predominant degradation products were identified: a 21-aldehyde and a 17-carboxylic acid. The 21-aldehyde is formed after TCA is oxidized by $\mathrm{O}_{2}$, a reaction that is catalyzed by trace metals. Logically, the content of trace metals has a profound effect on the degradation rate. It was shown that trace metals are extracted from lanolin and petrolatum by PG, increasing the concentration in PG. In accordance with these findings, TCA degrades faster in PG that is present in the ointment formulation than in regular PG. The 21-aldehyde was confirmed to be a primary degradation product, while the 17-carboxylic acid was identified as a secondary degradation product. Based on the mechanism of degradation, the ointment can be stabilized by the addition of sodium metabisulfite which was shown to reside also in the PG phase within the ointment.
\end{abstract}

KEY WORDS: Triamcinolone acetonide; Corticosteroid; Ointment; Trace metal; Degradation mechanism.

\section{INTRODUCTION}

Corticosteroids are widely used in a broad range of products. A selection of these products is for dermal application, such as ointments. In the Netherlands, TCA ointment $0.1 \%$ FNA (Formulary of Dutch Pharmacists) was available until it was withdrawn from the market after license holders reported poor chemical stability (1). The ointment consists of $0.1 \%$ TCA, $10 \%$ propylene glycol (PG), $10 \%$ lanolin, and $79.9 \%$ petrolatum. Various similar products are used worldwide.

TCA and molecularly similar corticosteroids are prone to oxidative degradation. This particular degradation predominantly occurs at the 17-side chain of the corticosteroid molecules (2-5). Amongst other degradation products, two are the most often mentioned for corticosteroids with the same 17-side chain as TCA (Fig. 1); first, a 21-aldehyde degradation product which formation is described in aqueous

\footnotetext{
${ }^{1}$ Department of Pharmaceutics, Utrecht Institute for Pharmaceutical Sciences, Utrecht University, 3584 CG, Utrecht, the Netherlands.

${ }^{2}$ Research and Development Department, Tiofarma B.V., Hermanus Boerhaavestraat 1, $3261 \mathrm{ME}$, Oud-Beijerland, the Netherlands.

${ }^{3}$ Department of Chemical Biology and Drug Discovery, Utrecht Institute for Pharmaceutical Sciences, Utrecht University, P. O. Box 80082, 3508 TB, Utrecht, the Netherlands.

${ }^{4}$ Department of Clinical Pharmacy, Division of Laboratory Medicine \& Pharmacy, University Medical Centre Utrecht, P/O Box 85500, 3508 GA, Utrecht, the Netherlands.

${ }^{5}$ To whom correspondence should be addressed. (e-mail: tvheugten@tiofarma.nl)
}

and alcoholic solutions (Fig. 1, compound 2). This 21aldehyde is formed by a reaction between TCA and molecular oxygen $\left(\mathrm{O}_{2}\right)$ that is catalyzed by metal salts (4). Second, for hydrocortisone and flurandrenolide the formation of a 17-carboxylic acid in alkaline environment was demonstrated by using $\mathrm{O}_{2}$ and $\mathrm{OH}^{-}$as reagents (2,3). Other degradation products concern degradation of the A ring (68) or hydrolysis of the acetonide moiety (9). For a water-free environment such as the TCA ointment, it was shown that the 21-aldehyde and 17-carboxylic acid are the main degradation products (10). The mechanism by which these are formed remains unclear however.

The aim of this study was to investigate the degradation mechanism of TCA in TCA ointment $0.1 \%$ FNA.

\section{MATERIAL AND METHODS}

\section{Chemicals and Reagents}

The following chemicals and reagents were used (all materials complied with the quality requirements of the European Pharmacopoeia (Ph. Eur. 2016)): TCA (Newchem, Milan, Italy), PG (Brenntag, Dordrecht, the Netherlands), lanolin (Stella Lanolines, Mouscron, Belgium), petrolatum (Sonneborn, Amsterdam, the Netherlands), copper(II) acetate $\left(\mathrm{Cu}(\mathrm{Ac})_{2}\right)$ (Alfa Aesar, Haverhill, MA, USA), tert-butyl peroxybenzoate (TBPB), sodium metabisulfite and 1,10phenanthroline (Sigma-Aldrich, St Louis, MO, USA), hexane and acetonitrile (Avantor Performance Materials, Center Valley, PA, USA), and phosphoric and acetic acid (Boom, 

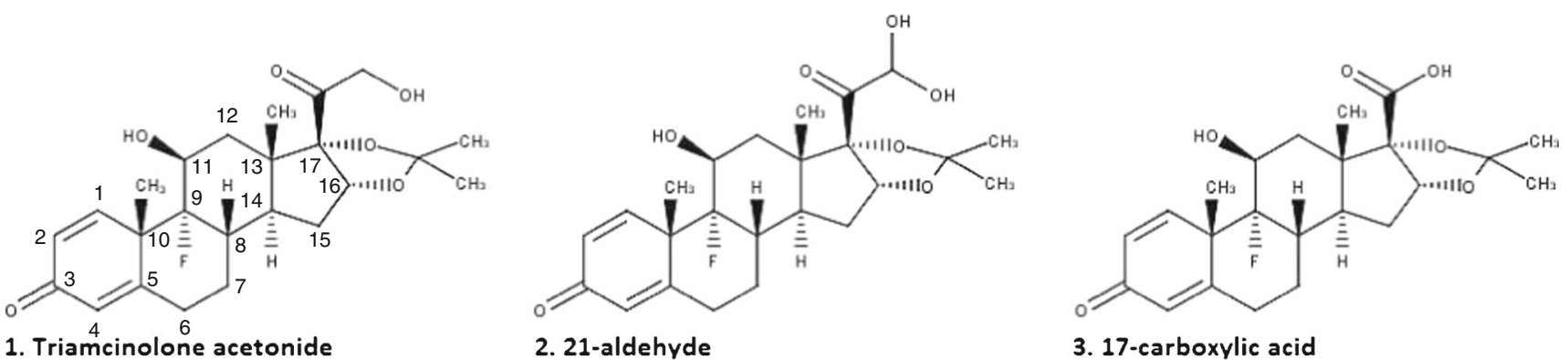

Fig. 1. Triamcinolone acetonide (TCA) and two degradation product as described for TCA and similar corticosteroids (2-5)

Meppel, the Netherlands). Distilled, deionized water was prepared by an Elga Centra R 60/120 system (Woodridge, IL, USA).

The Solubility of TCA in the Ointment Components and Microscopical Structure of TCA Ointment

One hundred grams of PG was added to an Erlenmeyer flask and heated to $60^{\circ} \mathrm{C}$ on a magnetic stirrer hot plate (IKA C-MAG HS4, Staufen, Germany). TCA was added in $0.25 \mathrm{~g}$ increments. One hundred grams of lanolin or petrolatum was added to stainless steel mortars that were heated to $60^{\circ} \mathrm{C}$ on a water bath (Ika Werke HB4 Basic, Strufen, Germany). TCA was added in $0.010 \mathrm{~g}$ increments. End point (solubility) was defined as the amount of TCA where solid dispersed particles were still observed after intensive stirring for $10 \mathrm{~min}$.

Additionally, TCA ointment sample was analyzed for microscopic structure using a light microscope (Euromex ME2880 microscope, Euromex, Arnhem, the Netherlands) with a magnification of $\times 40$.

\section{The Metal Content in the Excipients of the Ointment}

PG was mixed with lanolin and petrolatum in a ratio of 1:1:8 (i.e., the ratio of the ointment formulation). This mixture was stored at $60^{\circ} \mathrm{C}$ for 1 month. At $60^{\circ} \mathrm{C}$, the ointment is phase separated in a PG and a lanolinpetrolatum phase. The PG phase was separated from the lanolin-petrolatum phase by using a syringe. $0.5 \mathrm{~g}$ of this $\mathrm{PG}$ extract, normal PG, lanolin, and petrolatum were dispersed in $10 \mathrm{ml}$ nitric acid and $2 \mathrm{ml}$ of hydrogen peroxide in a Teflon tube in a MDS 2000 lab microwave (CEM Corporation, Matthews, NC, USA). After completing the microwave program (15 min $60 \%$ power and 80 psi; 15 min $80 \%$ power and 100 psi; and 30 min $90 \%$ power and 120 psi) the sample tubes were cooled, transferred to $50-\mathrm{ml}$ sample tubes and diluted to $30 \mathrm{~g}$ with water. Samples were analyzed using an inductively coupled plasma optical emission spectrometry (ICP-OES) spectrometer Dual-View Prodigy 7 (Teledyne Leemanlabs, Hudson, NH, USA) for iron, nickel, and copper content.

\section{LC Settings}

LC was conducted on a Shimadzu Prominence-i LC2030C 3D liquid chromatograph with diode array detector (Kyoto, Japan) and an Altima C18 column $(250 \times 4.6 \mathrm{~mm}$, with $5 \mu \mathrm{m}$ particles) (Mandel Scientific Company, Ontario, Canada). The flow rate was $1.5 \mathrm{~mL} / \mathrm{min}$, the injection volume was $20 \mu \mathrm{L}$ and UV detection was performed at $241 \mathrm{~nm}$. The mobile phase consisted of acetonitrile and water with the addition of $20 \mathrm{mM}$ phosphoric acid (acetic acid when subsequently analyzed with MS). A gradient program was used: $0 \%$ acetonitrile from start to $12 \mathrm{~min}$, increased to $32 \%$ at $12 \mathrm{~min}$, maintained at $32 \%$ until $30 \mathrm{~min}$, increased to $65 \%$ at $40 \mathrm{~min}$, decreased to $0 \%$ at $42 \mathrm{~min}$, and maintained at $0 \%$ until $47 \mathrm{~min}$. Chromatograms were obtained and analyzed with Shimadzu LabSolutions software version 5.5.7. This method is similar to a recently published analytical method for TCA ointment (10).

\section{MS Settings}

MS was conducted on an Agilent 1100 series ion-trap system equipped with an electrospray ionization (ESI) source and liquid chromatography sprayer (Agilent Technologies, Waldbronn, Germany) and operated in positive mode. Masses were scanned from m/z 50 to 600 , nebulizer pressure was $70 \mathrm{psi}$, gas flow was $12 \mathrm{~L} / \mathrm{min}$, gas temperature was $350^{\circ} \mathrm{C}$ and capillary voltage was $1600 \mathrm{~V}$. Data was analyzed with Agilent LC/MSD Trap 4.1 version 5.0 (build 65) software.

\section{RESULTS AND DISCUSSION}

The Microscopical Structure of the TCA Ointment and the Solubility of TCA in Ointment Excipients

Using a light microscope, the physical structure of the ointment appeared to consist of two phases, a dispersed phase in a more voluminous continuous phase. Since PG is more polar than lanolin and petrolatum, it seems logical to state that the dispersed phase consists of PG and the continuous phase of lanolin and petrolatum. The latter two are mixable, while these compounds hardly mix with PG. To study in what phase TCA resides within the ointment, solubility tests in the separate ingredients were conducted. The solubilities of TCA in PG, lanolin, and petrolatum were $1.25,<0.01$, and $<0.01 \%$, respectively. From this, it can be concluded that TCA is mainly present in the PG phase that is emulsified in a lanolinpetrolatum mixture. Therefore, degradation experiments in PG can be assumed to yield representative outcomes.

\section{The Identity of the Major TCA Degradation Products in the Ointment}

To elucidate the degradation mechanism of TCA, degradation products in the ointment were determined. Ointment was prepared and stored in closed glass containers 
Table I. TCA content after storage at $60^{\circ} \mathrm{C}$ for 7 days after exposure to six combinations of copper(II) acetate $\left(\mathrm{Cu}(\mathrm{Ac})_{2}\right)(0.16 \mathrm{mM}$, $10 \mathrm{ppm})$, purging air, and tert-butyl peroxybenzoate (TBPB) $(0.15 \mathrm{M}, 3 \%)$

\begin{tabular}{llll}
\hline $\mathrm{Cu}(\mathrm{Ac})_{2}$ & Air & TBPB & TCA content $( \pm \mathrm{RSD})$ \\
\hline- & - & - & $99.5( \pm 0.01)$ \\
- & + & - & $99.1( \pm 0.01)$ \\
- & - & + & $99.8( \pm 0.00)$ \\
+ & - & - & $80.3( \pm 0.02)$ \\
+ & + & - & $78.3( \pm 0.00)$ \\
+ & - & + & $96.1( \pm 0.10)$ \\
\hline
\end{tabular}

$T B P B$ tert-butyl peroxybenzoate, TCA triamcinolone acetonide, $R S D$ relative standard deviation

at $60^{\circ} \mathrm{C}$ for 1 month. Samples were analyzed using LC-MS. The two major degradation products were identified to be the 21-aldehyde and the 17-carboxylic acid (Fig. 1, compounds 2 and 3 , respectively) based on the $\mathrm{m} / \mathrm{z}$ ratios of 451.2 and 421.2, respectively. The 17-carboxylic acid showed a shift in retention time in response to mobile phase $\mathrm{pH}$ confirming it to be an acidic compound. To confirm that testing at $60^{\circ} \mathrm{C}$ shows a realistic degradation pattern, an old ointment that was stored for 5 years at room temperature was tested; the same degradation products were formed.

\section{The Degradation Mechanism of TCA}

The two degradants, 21-aldehyde and 17-carboxylic acid, are oxidative degradation products of TCA. They have been described before as degradants of hydrocortisone and TCA in aqueous and ethanolic solution in the presence of $\mathrm{O}_{2}$ and metal salts (2-4). For a water-free environment, it is unclear what reactants are present to oxidize TCA. In the ointment, the excipient lanolin is known to contain peroxide impurities (European Pharmacopoeia monograph 0134). Furthermore, the presence of trace metals cannot be excluded since excipients of natural origin are generally known to contain low levels of these (11). Therefore, a stress study was conducted to investigate whether TCA is oxidized by

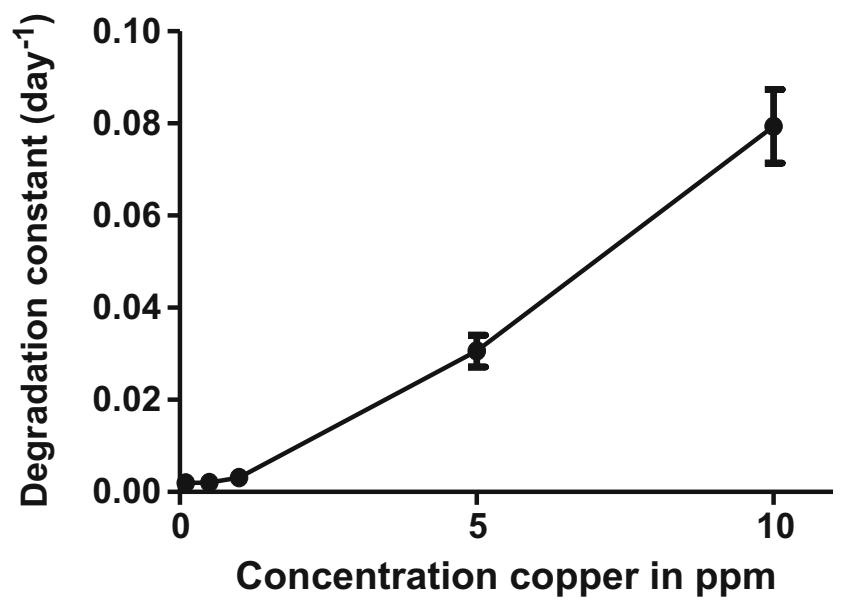

Fig. 2. Degradation constants of triamcinolone acetonide in propylene glycol spiked with different concentrations of copper(II) acetate at $60^{\circ} \mathrm{C}$. First order degradation constants are shown $(n=3 \pm 95 \% \mathrm{CI})$
Table II. Average $( \pm \mathrm{SD})$ trace metal content $(\mathrm{ppm})$ detected in the individual ointment excipients and in lanolin-petrolatum extracted with propylene glycol (PG) $(1: 8: 1)$ for 1 month at $60^{\circ} \mathrm{C}(n=4$ for PG and petrolatum, $n=3$ for lanolin, and $n=1 \mathrm{PG}$ extract)

\begin{tabular}{llrll}
\hline Metal & PG & \multicolumn{1}{c}{ Lanolin } & Petrolatum & PG extract \\
\hline Iron (in ppm) & $2.4 \pm 1.5$ & $11.9 \pm 8.8$ & $2.4 \pm 1.7$ & 5.6 \\
Nickel (in ppm) & $0.6 \pm 0.3$ & $1.5 \pm 1.9$ & $1.1 \pm 1.1$ & 0.8 \\
Copper (in ppm) & $0.5 \pm 0.3$ & $0.7 \pm 0.3$ & $0.8 \pm 0.3$ & 1.6 \\
\hline
\end{tabular}

$P G$ propylene glycol

peroxide residues and if its oxidation is catalyzed by trace metals in the non-aqueous ointment. TBPB was used as a model for organic peroxide residues (12). TCA was dissolved in $\mathrm{PG}$ and exposed to varying combinations of $\mathrm{Cu}(\mathrm{Ac})_{2}$, purging air, and TBPB (Table I). TCA content was determined after storage at $60^{\circ} \mathrm{C}$ for 7 days.

The results in Table I clearly show that without the presence of $\mathrm{Cu}(\mathrm{Ac})_{2}$, no clear degradation of TCA occurred. This indicates that the presence of air or peroxides alone does not initiate TCA degradation. However, when TCA was exposed to $\mathrm{Cu}(\mathrm{Ac})_{2}$, significant decomposition occurred. This is slightly increased by purging air in the presence of $\mathrm{Cu}(\mathrm{AC})_{2}$. Previously, it has been shown that TCA degradation is oxidative (2-4) and therefore, oxygen must be present in PG to react with TCA. To study whether sufficient oxygen is present in $\mathrm{PG}$, it was purged for 1 hour with nitrogen in the presence of $\mathrm{Cu}(\mathrm{Ac})_{2}$ in preliminary experiments $(90.3 \%$ TCA left for the purged and $85.9 \%$ for the untreated sample). Clearly, less degradation occurred in the purged PG compared to untreated PG. This clearly indicates that oxygen is indeed necessary for TCA to decompose and that in untreated PG sufficient oxygen is present to react with TCA.

Interestingly, the combination of $\mathrm{Cu}(\mathrm{Ac})_{2}$ and TBPB led to less degradation than $\mathrm{Cu}(\mathrm{Ac})_{2}$ alone (96.1 versus $80.3 \%$ ). A similar amount of decomposition was expected since the same amount of $\mathrm{Cu}(\mathrm{Ac})_{2}$ was present in the sample. It therefore appears that the peroxide (TBPB) and $\mathrm{Cu}(\mathrm{Ac})_{2}$ interact. Such interaction can possibly be explained by the Fenton-type reaction that occurs when trace metals $(\mathrm{M})$ react with peroxides (see Eqs. 1 and 2). Competition for $\mathrm{Cu}(\mathrm{Ac})_{2}$ between TBPB and TCA can explain the difference in degradation between the samples with $\mathrm{Cu}(\mathrm{Ac})_{2}$ alone and those with both $\mathrm{Cu}(\mathrm{Ac})_{2}$ and TBPB. Moreover, the hydroxyl radicals $(\mathrm{HO} \bullet)$ that form during Fenton-type reactions are much more reactive than the natural oxidant (ROO•) $(11,13)$. Even in this environment, TCA degraded less than in the presence of $\mathrm{Cu}(\mathrm{Ac})_{2}$ alone; affirming TCA oxidation is mediated by trace metals and oxygen rather than peroxides.

$$
\begin{aligned}
& \mathrm{M}+\mathrm{H}_{2} \mathrm{O}_{2} \rightarrow \mathrm{M}^{+}+\mathrm{HO} \bullet+\mathrm{OH}^{-} \\
& \mathrm{M}^{+}+\mathrm{H}_{2} \mathrm{O}_{2} \rightarrow \mathrm{M}+\mathrm{HOO} \bullet+\mathrm{H}^{+}
\end{aligned}
$$

\section{Influence of Storage Conditions}

As is shown above, the presence of air enforces TCA degradation. Therefore, an in use stability study was performed on a $0.5 \%$ TCA in PG:lanolin (1:1) mixture stored in 


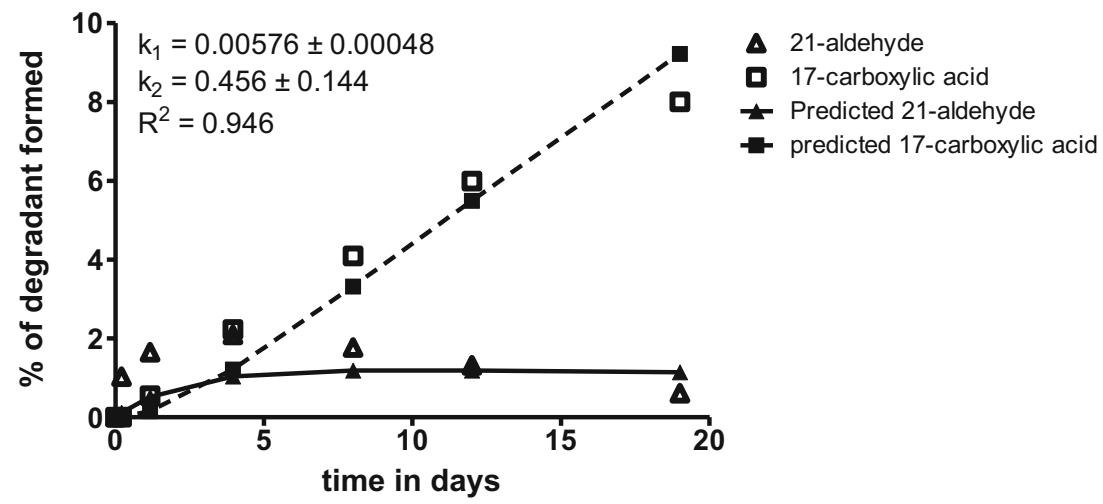

Fig. 3. Formation of the two major degradation products of triamcinolone acetonide (TCA) in the ointment formulation. The predicted values are based on degradation kinetics models presented in (15). For the experimental data $(n=3)$, a 95\% CI was calculated, error bars however were too small to be visible

closed glass containers and in glass containers that were opened twice a week for $10 \mathrm{~min}$. After 218 days at $60^{\circ} \mathrm{C}$ $96.8 \%( \pm 0.2)$ of TCA $( \pm$ RSD) was left in the closed containers while in the opened containers $73.1 \%( \pm 0.9)$ was left $(n=3)$. Clearly, TCA decomposes significantly faster in opened containers. When containers are opened, the sample is exposed to fresh air, allowing the supply of oxygen. Since in general, oxygen is more soluble in fatty environment compared to polar environment (14), it seems likely that opening containers twice a week is enough to replenish the oxygen concentration in the sample. Therefore, more substrate (oxygen) is available to react with TCA which can explain the higher TCA degradation.

\section{The Influence of Trace Metal Content on TCA Degradation Constant}

Metal salts greatly influence TCA degradation (4). To determine the relation between trace metal content and TCA degradation, a $0.5 \%$ TCA solution in $\mathrm{PG}$ was exposed to varying amounts of $\mathrm{Cu}(\mathrm{Ac})_{2}$ and equilibrated with air. $\mathrm{Cu}(\mathrm{Ac})_{2}$ was used as a model for other metal salts which are likely to react in a similar way $(2,4)$. TCA content was determined after 1 month. Figure 2 presents the results.

A clear concentration dependence of the degradation constant can be observed. TCA degraded completely in the 10 -ppm copper sample. In this sample, TCA is present in a concentration which is 75 times higher than the copper molar concentration. This shows that significantly more TCA degraded than copper was present, indicating that copper catalyzed the reaction. Copper, or other trace metals, as oxidation catalysts is further supported by literature $(2,11,13)$. This indicates that TCA oxidation can be catalyzed and hence, significantly increased even if only small traces of metal impurities are present.

\section{The Trace Metal Content in the Excipients of the Ointment}

Limits for trace metals in topical products are set in the European Pharmacopoeia (Ph. Eur. general text 5.20). Limits for copper and iron are 250 and $1300 \mathrm{ppm}$, respectively. Therefore, amounts $<250 \mathrm{ppm}$ are allowed to be present in lanolin, PG, and petrolatum. Commonly suspected trace metals, copper, iron, and nickel $(11,13)$ were determined using ICP-OES in the individual excipients. Additionally, lanolin and petrolatum were extracted with PG and analyzed as well. Table II shows the results.

Trace metal content differed between excipients. It is clear that lanolin and petrolatum contain more trace metals than PG. Interestingly, the saturated PG extract shows a higher level of trace metal content, showing that trace metals transfer to PG when exposed to lanolin and petrolatum. This extract was free from any undissolved lanolin and petrolatum since at $60^{\circ} \mathrm{C}$ the $\mathrm{PG}$ phase is phase separated from the lanolin-petrolatum mixture. Hence, it is to be expected that the metal content in the PG phase of the ointment increases when mixed with lanolin and petrolatum.

\section{The Influence of Lanolin and Petrolatum Extracted with PG}

As has been concluded above, TCA is predominantly present in the PG phase of the ointment. To check the influence of metals towards the TCA degradation, TCA was dissolved in PG and in lanolin and petrolatum extracted with PG. TCA content in this PG extract was determined after 16 days of storage at $60^{\circ} \mathrm{C}$ and compared to untreated PG. The remaining relative content was $85.2 \pm 0.5 \%$ and $97.2 \pm$ $0.04 \%$ for the PG extract and in the untreated PG, respectively. The faster degradation of TCA in the PG extract confirmed that the additional trace metals originating from the two excipients accelerate TCA degradation.

\section{The Degradation Pathway}

As described earlier, TCA degrades into the 21-aldehyde and the 17-carboxylic acid. To study how this degradation evolves, the ointment was stored at $60^{\circ} \mathrm{C}$ and samples were analyzed at various time points for TCA, 21-aldehyde and 17carboxylic acid content. Figure 3 presents the results.

Figure 3 shows that the 21-aldehyde content increases initially and subsequently levels and even slightly decreases

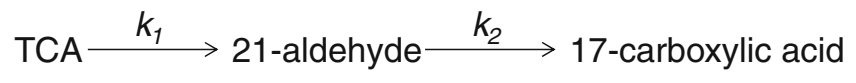
[A]
[B]
[C]

Fig. 4. Schematic overview of the TCA degradation route 

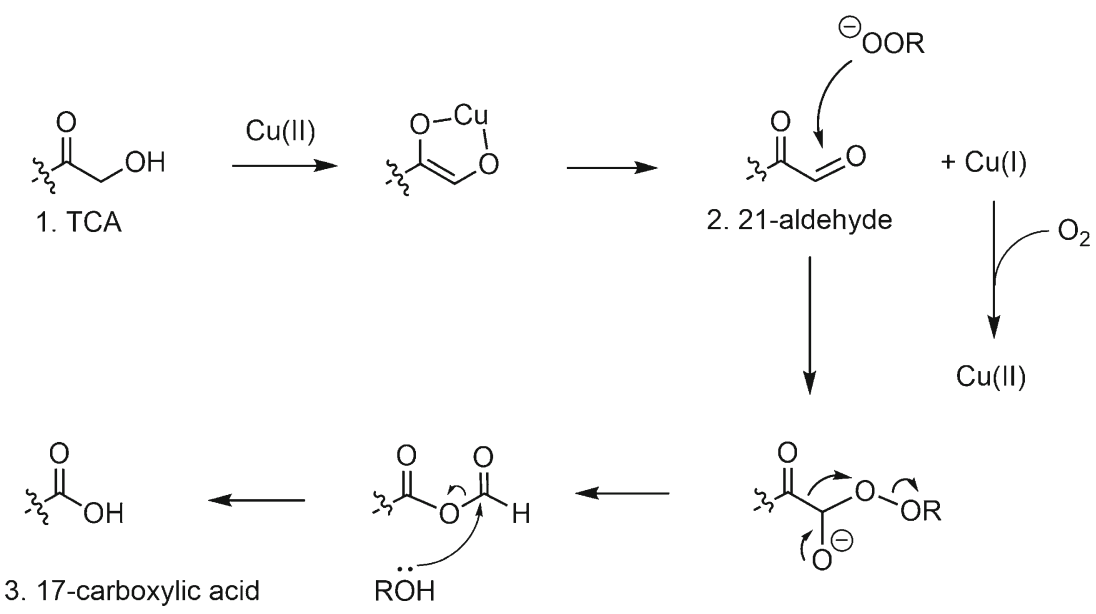

Fig. 5. Proposed degradation mechanism of the $\mathrm{C}_{17}$ side chain of triamcinolone acetonide (TCA) (component 1) in TCA ointment FNA to 21-aldehyde (component 2) and 17carboxyllic acid (component 3) $(16,17)$

after 3 days. The 17-carboxylic acid forms after a lag time of a few hours and the content increases subsequently. This points in the direction of a reaction from A (TCA) to B (21aldehyde) to $\mathrm{C}$ (17-carboxylic acid) (Fig. 4). This phenomenon has been described earlier by Waterman et al. (15). The degradation constants $\mathrm{k} 1$ and $\mathrm{k} 2$ can be calculated using Eqs. 3 and 4 .

$$
\begin{aligned}
& B_{t}=A_{0}\left[\frac{k_{1}}{k_{2}-k_{1}}\right]\left[e^{-k_{1} t}-e^{-k_{2} t}\right] \\
& C_{t}=A_{0}\left(1+\left[\frac{1}{k_{1}-k_{2}}\right]\left[k_{2} e^{-k_{1} t}-k_{1} e^{-k_{2} t}\right]\right)
\end{aligned}
$$

Using these equations, a degradation constant for the formation of the 21-aldehyde $\left(k_{1}\right)$ was calculated to be $0.00576 \pm 0.00048 \mathrm{day}^{-1}$ and for the formation of the 17caboxylic acid $\left(k_{2}\right) 0.456 \pm 0.144 \mathrm{day}^{-1}$. The fit for the equations was 0.946 further underlining the likelihood that the 17 -carboxylic acid is formed from the 21 -aldehyde in the ointment.

Since $k_{2} \gg k_{1}$, more of the 17 -carboxylic acid is present than 21-aldehyde shortly after the start of TCA degradation.
Based on the previously shown influence of trace metals and oxygen on the degradation of TCA, the following degradation mechanism can be proposed (Fig. 5).

Figure 5 indicates that the suggested sequence of degradation as shown in Fig. 4 is likely to occur according to the mechanism shown. The transformation of TCA to a 21aldehyde is likely to involve $\mathrm{Cu}^{2+}$ to form both the 21aldehyde and $\mathrm{Cu}^{+}$, which subsequently forms $\mathrm{Cu}^{2+}$ using oxygen (16). The degradation of a 21-aldehyde to a 17carboxylic acid has been reported for a corticosteroid with the same 17-side chain as TCA, betamethasone, using LC-MS isotope experiments using ${ }^{18} \mathrm{O}_{2}$ as the oxidant (17). When the two described mechanisms are linked, a water-free transformation of TCA to a 21-aldehyde and a 17-carboxylic acid is proposed. Potentially corticosteroids containing the same $\mathrm{C}_{17^{-}}$ moiety as TCA may degrade likewise. This is further supported by literature on for example hydrocortisone showing similar degradation products formed (2).

\section{The Prevention of TCA Degradation}

Since the degradation of TCA depends on $\mathrm{O}_{2}$ and trace metal content, the addition of a sacrificing antioxidant and a chelating agent could prevent degradation. To investigate the influence of such compounds, $0.1 \%$ sodium metabisulfite (11)

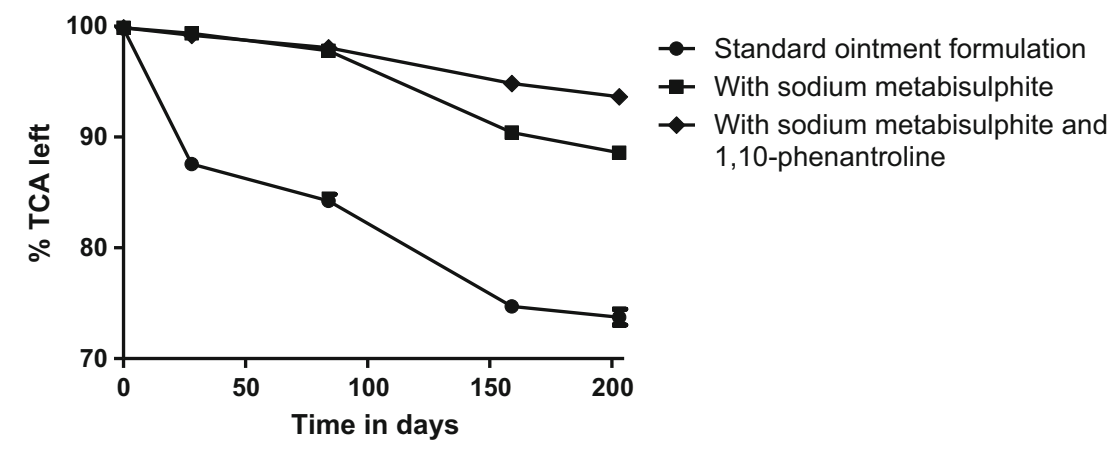

Fig. 6. The influence of the addition of $0.1 \%$ sodium metabisulfite and a combination with $0.1 \%$ 1,10-phenantroline to TCA ointment FNA formulation. Samples were stored in closed glass containers at $60^{\circ} \mathrm{C}$, measurements conducted in $n=3,95 \%$ CI shown in error bars 
and $0.1 \%$ 1,10-phenantroline as a chelating agent in organic environment (18) were dissolved in PG in combination with TCA and added to the lanolin-petrolatum mixture which was then stored at $60^{\circ} \mathrm{C}$ for over 6 months in Erlenmeyer flasks. An ointment without additional ingredients was stored as well. Figure 6 presents the results.

Figure 6 clearly shows that sodium metabisulfite stabilizes TCA in the ointment showing that it can work as a sacrificing antioxidant in organic environment. The addition of 1,10-phenantroline shows an additional stabilizing effect. Logically, 1,10-phenantroline will sequester metals and thereby decrease the available amount of catalytic metals to react with TCA.

\section{CONCLUSION}

Oxidation of TCA takes place in the PG phase of the ointment. This oxidation is catalyzed by trace metals which are extracted from lanolin and petrolatum. An extensive degradation mechanism is proposed based on these findings. Sodium metabisulfite stabilized TCA in the ointment and 1,10-phenantroline shows an additional improvement when combined with sodium metabisulfite.

Funding This work was supported by the R\&D tax credit of the Ministry of Economic Affairs, the Netherlands (grant number S016053527).

Open Access This article is distributed under the terms of the Creative Commons Attribution 4.0 International License (http://creativecommons.org/licenses/by/4.0/), which permits unrestricted use, distribution, and reproduction in any medium, provided you give appropriate credit to the original author(s) and the source, provide a link to the Creative Commons license, and indicate if changes were made.

\section{REFERENCES}

1. Scientific Institute for Dutch Pharmacists. Triamcinolonacetonidezalf $0,1 \%$-commentaar. In: Formularium der Nederlandse Apothekers (FNA), 4th edition. 2009. p. 232-4.

2. Hansen J, Bundgaard H. Studies on the Stability of Corticosteroids V. The Degradation Pattern of Hydrocortisone in Aqueous Solution. Int J Pharm [Internet]. 1980 Sep [cited 2017 Mar 1];6(6):307-19. Available from: http://linkinghub.elsevier.com/ retrieve/pii/0378517380901143

3. Pearlman R, Rutherford BS, Pozsgai KM, Hirsch CA. The isolation and identification of some degradation products of flurandrenolide in Cordran cream. Int J Pharm. 1984;18(12):53-65. https://doi.org/10.1016/0378-5173(84)90107-8.

4. Wu ZZ, Thatcher ML, Lundberg JK, Ogawa MK, Jacoby CB, Battiste JL, et al. Forced degradation studies of corticosteroids with an alumina-steroid-ethanol model for predicting chemical stability and degradation products of pressurized metered-dose inhaler formulations. J Pharm Sci [Internet]. Elsevier Masson
SAS; 2012;101(6):2109-2122. Available from: https://doi.org/ $10.1002 /$ jps.23111

5. Lewbart ML, Mattox VR. Conversion of Steroid-17-yl Glyoxals to Epimeric Glycolic Esters1. J Org Chem [Internet]. 1963;28(7):1779-86. Available from: https://doi.org/10.1021/ jo01042a011.

6. Miolo G, Ricci A, Caffieri S, Levorato L, Fasani E, Albini A. In Vitro Phototoxic Properties of Triamcinolone 16,17acetonide and Its Main Photoproducts. Photochem Photobiol [Internet]. Blackwell Publishing Ltd; 2003 1;78(5):425-30. Available from: https://doi.org/10.1562/00318655(2003)0780425IVPPOT2.0.CO2.

7. Ricci A, Fasani E, Mella M, Albini A. Noncommunicating photoreaction paths in some pregna-1,4-diene-3,20-diones. J Org Chem. 2001;66(24):8086-93. https://doi.org/10.1021/ jo015884z.

8. Williams R, Moore IRH, Li R, Weekslc CM. Photochemistry of $11 \alpha$ - and $11 \beta$-hydroxy steroidal 1,4-Dien-3-ones and $11 \alpha$ - and $11 \beta$-hydroxy steroidal Bicyclo[3.1.0]hex-3-en-2-ones in neutral and acidic media. J Org Chem. 1980;45(12):2324-31. https:// doi.org/10.1021/jo01300a012.

9. Timmins P, Gray EA. The degradation of triamcinolone acetonide in aqueous solution: influence of the cyclic ketal function. J Pharm Pharmacol [Internet]. Blackwell Publishing Ltd; 1983 1;35(3):175-7. Available from: https://doi.org/10.1111/ j.2042-7158.1983.tb04300.x.

10. van Heugten AJP, de Boer W, de Vries WS, Markesteijn CMA, Vromans H. Development and validation of a stabilityindicating HPLC-UV method for the determination of triamcinolone acetonide and its degradation products in an ointment formulation. J Pharm Biomed Anal [Internet]. Elsevier B.V.; 2018 149:265-70. Available from: https://doi.org/10.1016/ j.jpba.2017.11.026.

11. Waterman KC, Adami RC, Alsante KM, Hong J, Landis MS, Lombardo F, et al. Stabilization of pharmaceuticals to oxidative degradation. Pharm Dev Technol. 2002;7(1):1-32. https:// doi.org/10.1081/PDT-120002237.

12. $\mathrm{Xu} \mathrm{J}$, Gleason KK. Conformal polymeric thin films by lowtemperature rapid initiated chemical vapor deposition (iCVD) using tert-butyl peroxybenzoate as an initiator. ACS Appl Mater Interfaces. 2011;3(7):2410-6. https://doi.org/10.1021/ am200322k.

13. Boccardi G. Oxidative Susceptibility Testing. In: Pharmaceutical Stress Testing: Predicting Drug Degradation [Internet]. 2005 [cited 2017 May 23]. p. 205-34. Available from: http:// www.crcnetbase.com/doi/abs/10.1201/9780849359194.ch7

14. Chaix E, Guillaume C, Guillard V. Oxygen and carbon dioxide solubility and diffusivity in solid food matrices: a review of past and current knowledge. Compr Rev Food Sci Food Saf. 2014;13(3):261-86. https://doi.org/10.1111/1541-4337.12058.

15. Waterman KC, Swanson JT, Lippold BL. A scientific and statistical analysis of accelerated aging for pharmaceuticals. Part 1: accuracy of fitting methods. J Pharm Sci. 2014;103(10):3000-6. https://doi.org/10.1002/jps.24075.

16. Liang H, Liu H, Jiang X. Research on the conversion of alphahydroxy ketones into 1,2-diketones and subsequent transformations. Synlett. 2016;27(20):2774-82.

17. Li M, Chen B, Monteiro S, Rustum AM. Mechanism of basecatalyzed autooxidation of corticosteroids containing 20-keto21-hydroxyl side chain. Tetrahedron Lett [Internet]. Elsevier Ltd; 2009;50(32):4575-81. Available from: https://doi.org/ 10.1016/j.tetlet.2009.05.074.

18. Sun C, Wu Y, Zhang W, Jiang N, Jiu T, Fang J. Improving efficiency by hybrid $\mathrm{TiO} 2$ nanorods with 1,10-phenanthroline as a cathode buffer layer for inverted organic solar cells. ACS Appl Mater Interfaces. 2014;6(2):739-44. https://doi.org/10.1021/ am404423k. 